DOI: 10.21625/resourceedings.v2i3.628

\title{
Innovative methods of the representation: in painting, in sculpture and in cinematographic direction
}

\author{
Luca $\operatorname{Izzo}^{1}$ \\ 1 University of Campania "Luigi Vanvitelli" \\ Department of Architecture and Industrial Design \\ PhD student XXXIV cycle (SSD L.ART / 06 - Cinema, Television and Photography)
}

Email: luca.izzo@unicampania.it

\begin{abstract}
The object of study is a search for the strategies of representation of the four dimensions, three spatial and one temporal, when these dimensions become particular "media-conceptual", creating "space-time" experiments, sometimes sacred and sometimes profane. The research recognizes cases in which the four dimensions have been realized with innovative methodologies, different from the traditional geometric-perspective methodologies. The research analyzes the transformation of "sacred space" into "profane space" in Gustave Courbet's painting, then the "sacred space-time" dimension in Michelangelo Buonarroti's Vatican Pietà, while, in the second part of the research, the reflection on "places of images", through the cinema of Charlie Chaplin, the film Memento by Christopher Nolan, the spiritual minimalism of Kasimir Malevic and the sculpture by Piero Manzoni.
\end{abstract}

The study focuses on the contemporary age, with only one opening on the fifteenth century, modern age, thanks to the exceptional "contemporaneity" of Michelangelo Buonarroti.

(c) 2019 The Authors. Published by IEREK press. This is an open access article under the CC BY license (https://creativecommons.org/licenses/by/4.0/).

Keywords

Communication; space; dimension; time.

\section{Introduction}

The research started with a very interesting experimentation by the french painter Gustave Courbet, when, in the year 1850 , he created the work Funeral in Ornans

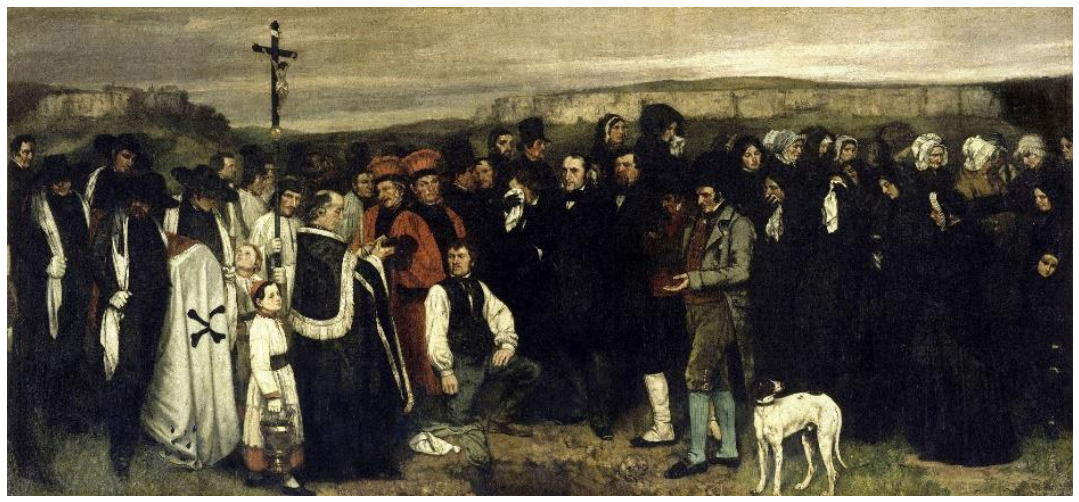

. Figure 1. Un enterrement à Ornans, Gustave Courbet (1850). 
In this work, Gustave Courbet, overturning the artistic canons of the western figuretive tradition, builds and communicates the environment around the characters not through drawing and geometry, but through the pictorial image as a whole, or through "conceptual canons" and not "geometric canons". We can read it from the clothes of the characters who, on our left, are well-dressed, from the gentlemen with the hats and with gloves, to the clergy of the city, varied in roles and well-dressed.

In Funeral ad Ornans we are in a suburban village near a city. But what do we understand from this as the city does not even appear in the background, as the more traditional iconography used to represent?

While, on our right, we can see characters from the rural suburbs, represented with humble and crumpled clothes, on our left, instead, are depicted characters of the city clergy, with their most precious clothes.

The viewer understands that the scene takes place in a campaign of suburbs thanks to the faces and clothes of the participants, some easily traceable to the city clergy, others easily attributable to the popular class (Colombo, Dioniso, Onida \& Savarese, 2016, p. 273)

Courbet, in this work, destroys the canons and communicative conventions of the occidental pictorial language, "communicating through an empty space — the moat — who is the protagonist of the work", which, extraordinarily and for the first time in the history of the arts, is not even represented.

The Funeral in Ornans is therefore the first work - in the history of art - which did not represent the "protagonist of the story", creating a "material and conceptual space" - the moat - "imaginary and imagined", in which, that "void", the absence, becomes a "presence". So what's in the empty ditch? Who is the deceased?

Reconstructing the thought and contents of Courbet's research, it seems that the artist, in that moat, wanted to represent his desire to see "academic art" dead, "outdated".

Later the research wanted to go back in time, identifying an extremely original use of the "three spatial dimensions", in which the characters were represented in order to suggest the "fourth dimension", the "temporal" dimension, represented in "a dimension sacred and conceptual" at the same time.

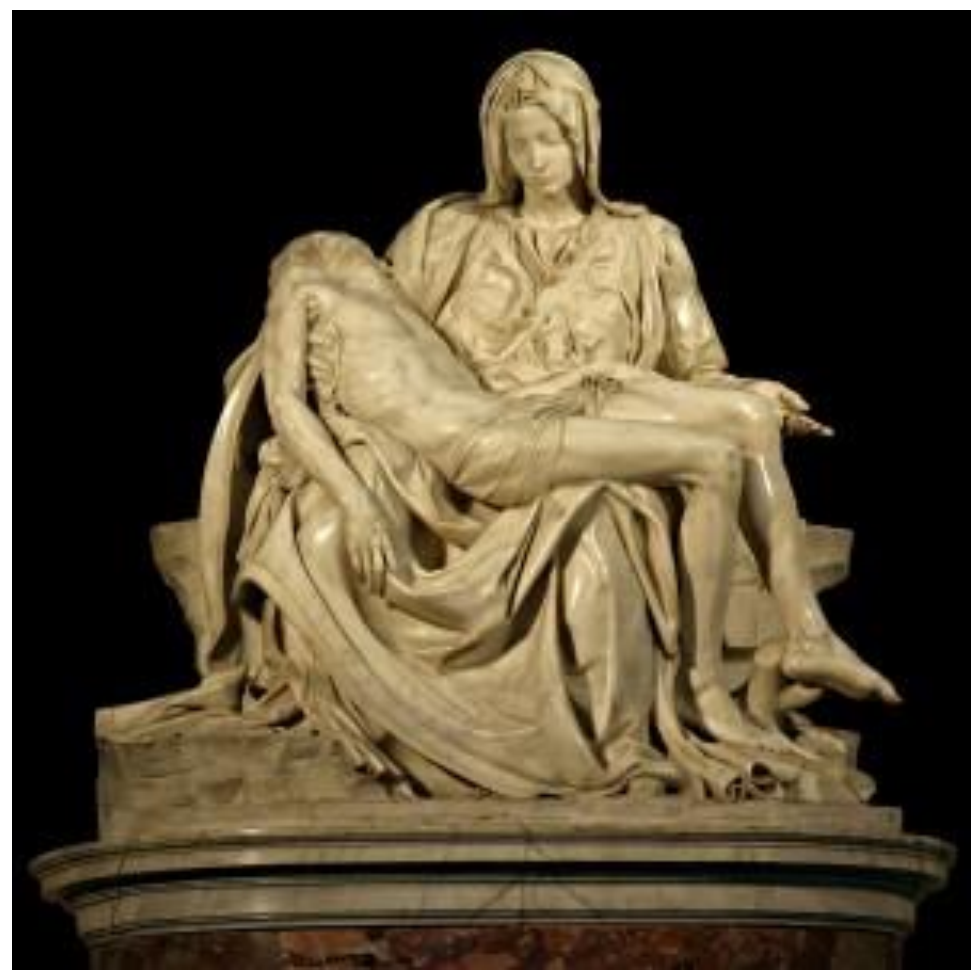

Figure 2. Vatican Pietà, Michelangelo Buonarroti (1499).

Michelangelo Buonarroti, in the Vatican Pietà, manipulates and distorts the "temporal dimension" by how he arranges the characters in three-dimensional space. The author, placing the body of Christ horizontally in the arms of the Mother, creates a "space-time frame" and, within it, in a single represented image, "there is the first and last image 
of Christ in the relationship with the Mother", or the newborn Christ, horizontally lying in the arms of the Mother, plus the dead adult Christ, detached from the cross and delivered into Mary's arms. A frame that "creates eternity": the two characters are like "suspended in time"; time is blocked, "crystallized", and it is also read on the face of the Virgin, who was represented much younger compared to the age of Mary at that time. "Past and present" coexist and interpenetrate, opening up a dimension of "sacred eternity".

Buonarroti indicated his source in the words of Dante Alighieri, in the work La Divina Commedia (Paradise), "Virgin and Mother, daughter of your son" (Risaliti \& Vossilla, 2015, p.118).

We must not forget that only two years later, Michelangelo began the work Madonna with child, today in Bruges (Belgium), in which there is another operation of "space-time reference", this already recognized by academic studies. The child who goes away from the arms of the Mother, to walk alone, is a symbol of the knowledge of his destiny as an adult, the sacrifice he will have to make to redeem humanity.

Returning to the contemporary, to the work of the directorial genius of Charlie Chaplin, in his debut in the cinema he builds a film (duration 6 minutes, as of use in that epoch) that destroys the spatial limits between "reality and stage fiction" (Robinson, 2006, pp. 149-146). Chaplin suddenly charged with going to the place of a popular party in Venice, the Los Angeles neighborhood, to shoot some comic sketches using the background with scenes of artisan car racing he invents, for the first time in history, his costume the little fellow (called the tramp, or Charlot), to interact, improvising, with the public and with the event. With this film, entitled Kids Auto Races in Venice, California,

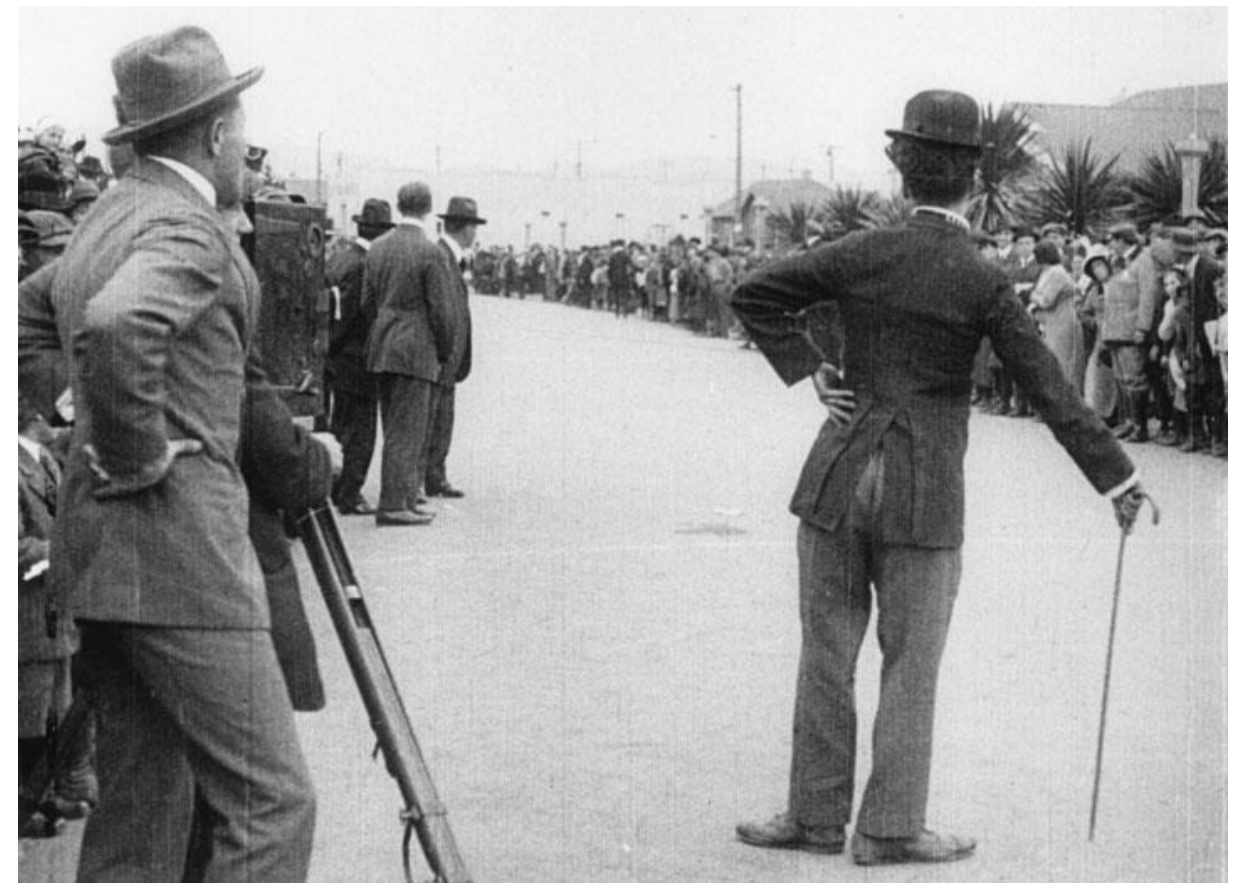

Figure 3. Kid Auto Races in Venice, Charlie Chaplin (1914).

Chaplin makes the first reality show in history, the first candid camera, in 1914, creating a "new space-conceptual dimension between reality and fiction" (Farinelli \& Cenciarelli, 2010, p.7).

Chaplin's art becomes even more effective when, in the same year, the artist creates the work A Film Johnnie, in which the little fellow - after falling in love with a woman seen exclusively through a billboard — in the cinema room he lives all the emotions he can experience, from love to anger, to jealousy. Chaplin destroys the dimension of the projection screen, combining representation and artistic communication with the human perceptive and emotional dimension. 


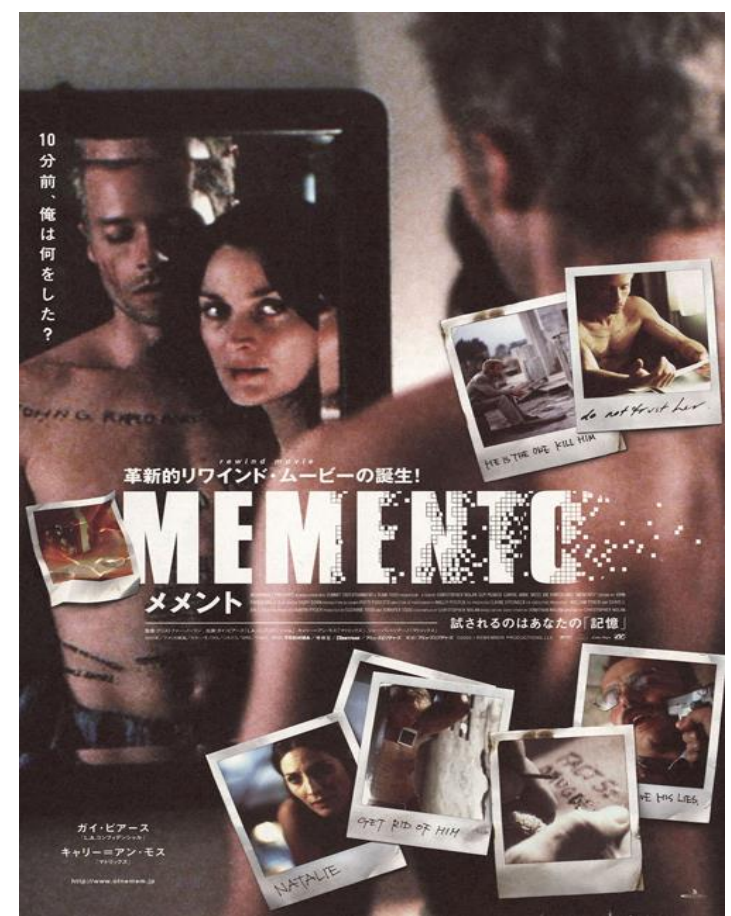

Figure 4. Memento, Christopher Nolan (2000).

Christopher Nolan, in his film Memento (2000), has created a still different space-time solution: the past, present and future exchange roles, and the film, are very innovative, "has been mounted upside down", that is from the last scene to the first scene, so time goes "from the future to the past". Nolan takes us into the reality of a man suffering from "anterograde amnesia", a pathology that does not remember information for more than fifteen minutes. The character's actions are all to reconstruct what happened to him previously, so the "film time" it is reversed and made to evolve on the contrary, while instead the "real time", the time of the spectator's life, evolves regularly. The viewer goes into a very particular "cognitive-temporal" state, but this state is still understandable and effective for filmic communication.

Another original solution is the one used by different artists of the twentieth century "avant-garde". In particular, to remain in the area of a space-conceptual manipulation, the research of the Ukrainian artist Kasimir Malevich is very interesting.

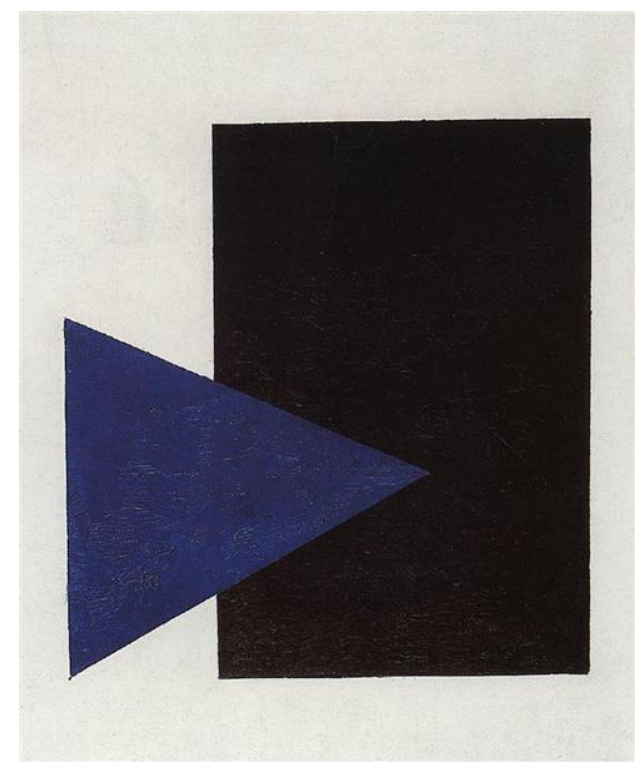

Figure 5. Triangolo blu e rettangolo nero, Kasimir Malevic (1915). 
The "four-dimensional space" is contracted by half, leaving only two dimensions, width and height (Dorfles \& Vettese, 2009, p.p. 144-147, p.169), while, on the contrary, a "sacred space" is opened, which in the perfection of geometry, finds its ancestral, semantic and anthropological roots.

All the space, sacred and profane, in all its dimensions, is completely included in the work Base Del Mondo, by the Italian artist Piero Manzoni (Dorfles et al., 2009, pp. 369-370).

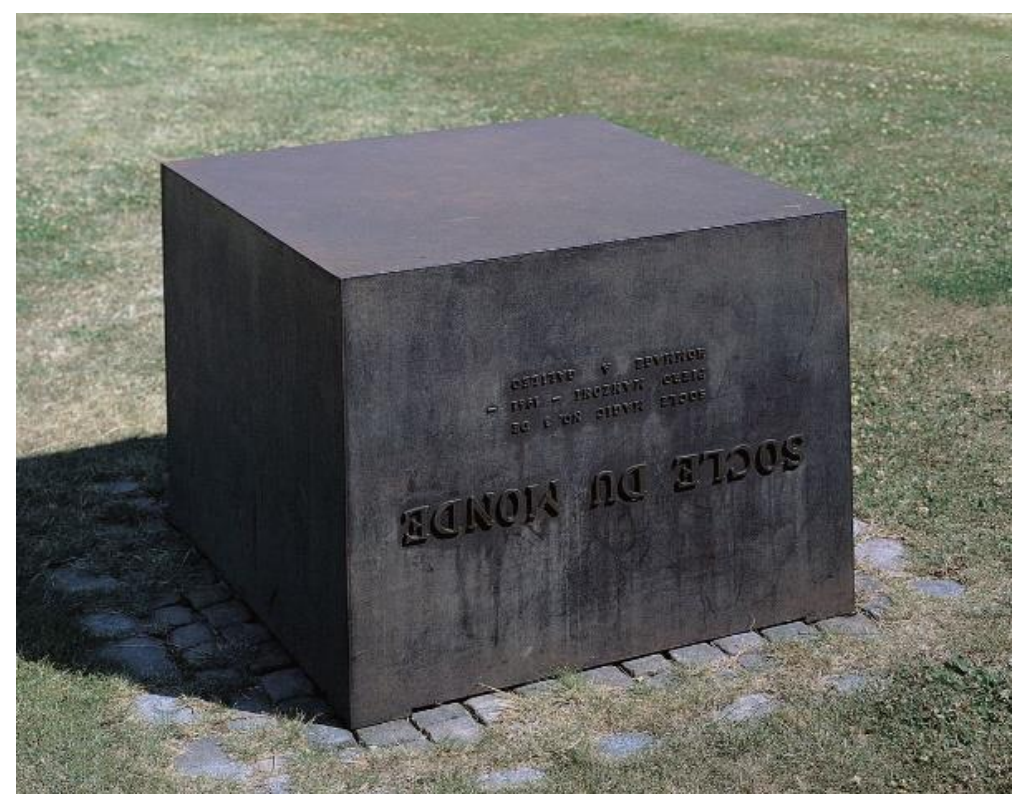

Figure 6. Base del mondo, Piero Manzoni (1961)

In this work, space is not realized as "simple artificial and illusory reproduction", as it had always been done in human artistic representations, but the work of art becomes the "real and real space of the whole world around us". This metallic cube is the basis of a contemporary sculpture put in reverse, therefore — given that the "high" and "low" directions are exclusively human cultural conventions and do not exist in nature, in the universe - this allows that "on that basis" there is all the "real world", our whole planet. The work of art, therefore, is the whole concrete world that we know: we who move, act, live, think and love on this world. Every aspect of existence is part of the work. Also, all the sacred places and the sacred rites that, in every place of the world, humanity has built and still builds.

\section{Conclusions}

The study wanted to trace different cases, in different artistic languages, in which the communication of space and time, sacred or profane, was realized not through the traditional mathematical-geometric methods, but, instead, through innovative solutions.

All these experiments have been analyzed to demonstrate how in the potential of human linguistic-communicative imagination, in all the media and the techniques for emitting messages, there are always the possibilities to open new horizons and new semantic systems of interpersonal communication. These infinite processes are the basis of the system and the production of the cultural goods of the "human community".

\section{References}

Colombo, L.C., Dioniso, A.D., Onida, N.O., \& Savarese , G.S. (2016). Opera, Architettura e Arti Visive nel Tempo. Milano, Italia: Bonpiani Editore.

Dorfles, G.D. \& Vettese, A.V., (2009). Storia dell'Arte. Bergamo, Italia: Atlas Editore.

Dorfles, G.D. \& Vettese, A.V., (2009b). Storia dell'Arte. Bergamo, Italia: Atlas Editore.

Farinelli, G.F. \& Cenciarelli, C.C., (2010). C. Chaplin. Le comiche Keystone. Bologna, Italia: Cineteca Bologna.

Nolan, CN, (2000). Memento. Movie. U.S.A.: Newmarket Capital Group.

Risaliti, S.R., \& Vossilla, F.V., (2015). La Pietà Vaticana. Milano, Italia: Bonpiani Editore.

Robinson, D.R., (2006). Chaplin. L'arte e la vita. Venezia, Italia: La Biblioteca di Repubblica. 